\title{
GLOKALISASI SPASIO-TEMPORAL DALAM AGAMA ALUK TO DOLO OLEH AGAMA KRISTEN DI TORAJA
}

\author{
Stanislaus Sandarupa \\ Fakultas Sastra Universitas Hasanuddin \\ Jl. Perintis Kemerdekaan (km 11) Makassar \\ Email: torindo@indosat.net.id
}

\begin{abstract}
Abstrak:Penelitian ini membahas proses glokalisasi dalam agama Aluk To Dolo yang dilakukan oleh penganut Kristen Toraja untuk diintegrasikan ke dalam agama barunya. Pengumpulan data memakai metode etnografi yaitu participant observation dengan teknik perekaman, video, dan catatan lapangan. Penelitian dilakukan di Toraja induk seperti Makale, Mengkendek dan Sangngalla' dan di Toraja utara dengan memusatkan penelitian pada tiga kasus, yaitu pada pranata tongkonan, sistem ritual dan seni patung. Proses glokalisasi dalam ketiga kasus itu memperlihatkan persamaan dan perbedaannya. Penganalisisan data dilakukan dengan interpreasi langsung yang digabung dengan analisis narasi.Konsep dualistis agama Aluk To Dolo yang berkonflik dengan konsep monoteisme Kristen melatarbelakangi proses glokalisasi dalam ketiga kasus yaitu pranata tongkonan, sistim ritual, dan seni patung. Monoteisme merupakan kriteria utama dalam mengevaluasi Aluk To Dolo. Akibatnya banyak praktik ritual yang dihapuskan. Dalam hal itu agama Kristen global bersifat hegemonik. Namun masyarakat lokal Kristen memakai strategi untuk mempertahankan unsur lokal agamanya. Masyarakat mempunyai kejeniusan lokal untuk membangun keharmonisan kedua elemen budaya yang direkayasa pada dialektika spasio-temporal. Berdasarkan temuan itu disimpulkan bahwa globalisasi tidak selalu hegemonik pada agama lokal. Masyarakat Kristen setempat mempunyai kearifan lokal dalam membangun keharmonisan kedua elemen yang berpusat pada ekstensi spasiotemporal.
\end{abstract}

Kata kunci: dialogisme, glokalisasi budaya, spasio-temporal, Kristen dan Aluk To Dolo

\section{THE SPATIO-TEMPORAL GLOCALIZATION OF THE ALUK TO DOLO RELIGION BY CHRISTIANS IN TORAJA}

\begin{abstract}
This research discusses the process of glocalization of Aluk To Dolo by the Torajan Christians who integrate the local elements into their new religion. The data collection employs ethnographic method, that is participant observation using the techniques of recording, videotaping, and notetaking. The research was carried out in the Main Toraja in the villages of Makale, Mengkendek, and Sangngalla', and in the North Toraja in Rantepao town. The research focuses on three cases, that is, the tongkonan institution, ritual system and the art of effigy. It concentrates on the theme of glocalization by looking at the similarities and the differences among the three cases. The data are analyzed by direct interpretation combined with narration. It is found that the Aluk To Dolo practices of dualism in the local belief system (ancestors and deities) is in conflict with Christian's monotheistic belief as can be observed in three aspects of religious practices in the tongkonan institution, ritual system, and ancestral figure. It is this monotheistic concept that has been used to evaluate the local religion. As a result, many local ritual practices were abolished. In that case the global Christianity is hegemonic to the local one. However, the Torajans use various strategies to defend their local belief practices. Such strategies employ the local genius of harmony in constructing the dialectal spatio-temporal relation between the two. Based on these findings, we can conclude that globalization is not always hegemonic to the local religion. The local people have a number of local wisdoms to construct the harmonious relation between the two based on the extension of spatio-temporal dimensions.
\end{abstract}

Key words: dialogism, glocalization of religion, spatio-temporal, Christianity dan Aluk To Dolo

\section{PENDAHULUAN}

Ketika Indonesia merdeka bahkan ketika agamaagama besar dunia datang, timbul permasalahan tentang proses interaksi agama-agama luar dengan agama-agama lokal dan aliran kepercayaan dalam berbagai kelompok etnis di Indonesia.

Penelitian ini mengemukakan bagaimana salah satu kehidupan kelompok etnis Indonesia, masyarakat Toraja, setelah menerima agama Kristen (Protestan dan Katolik) berupaya mempertahankan unsur-unsur agama lokalnya, Aluk To dolo (Agama Leluhur) yang diintergrasikannya ke dalam agama baru.

Kebudayaan Toraja seperti upacara kematian yang terkenal tak dapat dipisahkan dari agama, bahkan ia bersumber dan mendapatkan inspirasi dari agama lokal. Agama lokal ini disebut Aluk To Dolo (Aluk berarti “Agama", To berarti “orang” dan Dolo berarti, "Leluhur"). Biasa juga disingkat Alukta (Agama dimana sufiks ta berarti "Kita"). Konsep-konsep tentang Agama Leluhur tersimpan dalam teks-teks tradisi lisan yang mengonstruksi kehidupan dan hubungan sosial, yaitu membangun obyek-obyek, dunia, dan ide. Teks-teks dalam berbagai bentuk, seperti peribahasa, mitos, cerita, pemali, dan berbagai ungkapan lainnya, secara sistematis mengatur relasi manusia dengan dunia sakral (dewa-dewa dan leluhur), manusia dengan manusia, dan manusia dengan lingkungannya (Sandarupa 2007).

Tema paling mencolok ialah cita-cita untuk mencapai kehidupan ekologis yang harmonis. Agama Aluk To Dolo melembagakan praktikpraktik pengetatan pelaksanaan ajaran, aturan, dan 
tatanan kehidupan sosial. Masih dipraktikkan sekitar 5 persen penduduknya (Biro Statistik 2010) dan sudah dilindungi oleh negara serta resmi diterima ke dalam sekte Hindu-Bali pada tahun 1969, agama ini bersumber dari dua ajaran utama, pertama, yang disebut Aluk 7777 atau Aluk Sanda Pitunna ("Aluk Yang Serba Tujuh"), dan kedua, Aluk Sanda Saratu' ("Aluk Yang Serba Seratus"). Baik Aluk Sanda Pitunna yang disebarkan Tangdilino' maupun Aluk Sanda Saratu' yang disebarkan Puang Tamborolangi' dipercayai turun dari langit.

Masyarakat Toraja patut berbangga karena mempunyai mitos penciptaan yang dikonstruksi dalam satu teks yang terdiri atas ribuan baris paralel yang disebut Passomba Tedong, "persembahan kerbau kepada Yang Kuasa" (Veen 1965). Teks ini dinarasikan semalam suntuk, disertai persembahan seekor kerbau kecil ke Yang Kuasa pada waktu melakukan upacara rumah (tongkonan). Muncul dalam bentuk paralelisme sebagai ciri tuturan ritus setempat, teks tradisi lisan ini dipelihara, dikontrol, dan dikuasai serta dituruntemurunkan secara genealogis oleh sekelompok pemimpin upacara rambu tuka' (upacara kehidupan), yaitu tomina dan tomenani.

Di dalam teks itu diceriterakan antara lain tentang kosmologi dan teogoni agama ini. Sebagaimana budaya Austronesia, dalam agama ini dipercayai adanya perkawinan langit dan bumi yang melahirkan dewa-dewa. Salah satu yang membedakan agama ini dengan yang Kristen adalah dualitas dalam keperyaaan yaitu kepercayaan kepada Dewa-Dewa dan kepercayaan kepada kekuatan Arwah Leluhur. Leluhur merupakan Dewa (To Membali Puang yang berarti "Menjadi Dewa"). Leluhur tidak bisa dipisahkan dari rumah tradisional tongkonan berbentuk perahu.

Sistem ritualnya disbeut Aluk Tallu Lolona, A'pa' Tauninna yang artinya "Upacara Yang Terdiri Atas Tiga Pucuk Kehidupan Dan Empat Tembuni”. Disebut tiga aluk karena ia meliputi upacara menyangkut manusia (aluk tau), upacara tanam-tanaman (aluk tananan), dan upacara menyangkut hewan (aluk patuan). Dikatakan empat karena di samping ketiga hal di atas ada lagi satu upacara yang disebut upacara menebus kesalahan (suru' pengkalossoran). Satu yang terpenting dari situ ialah rambu solo' yaitu upacara kematian yang berpasangan dengan rambu tuka', yaitu upacara mentransformasi arwah hitam dan menakutkan seseorang yang baru meninggal (bombo) menjadi roh menuju Puya (bombo mendeatanna) menjadi dewa di langit (to membali puang).

Sejumlah antropolog telah meneliti berbagai aspek agama Aluk To Dolo. Misalnya, Nooy-Palm menghasilkan ulasan tentang kehidupan sosial dan agama di Toraja secara sinkronis (Nooy-Palm 1979; Nooy-Palm 1986) dan politik di Toraja (Crystal 1989) dan sistem ritual (Koubi 1982). Ada beberapa yang menulis tentang perubahan yang terjadi dalam masyarakat Toraja (Acciaioli 1985; Adams 1988; Adams 1990; Adams 1991; Volkman 1985) dan ada yang menulis tentang sejarah sosial Toraja (Bigalke
2005), transformasinya (Roxana 2009) serta sastrasastra lisan Toraja (Sandarupa 2004; Veen 1965; Veen 1966). Dalam bukunya, Bigalke membahas perubahan yang terjadi di Toraja dalam kurun waktu 18601942 yang terdiri atas tiga epok (Bigalke 2005:xxii). Pertama, gambaran interaksi dengan masyarakat dataran rendah terutama dengan masyarakat Bugis tahun 1860-1904. Perdagangan kopi dan hamba antara keduanya menimbulkan perubahan dalam pola-pola kepemilikan tanah. Kedua, kedatangan dan pendudukan Belanda tahun 1905-1941. Kajian berpusat pada jawaban masyarakat ini terhadap penjajahan Belanda, perubahan agama, masuknya pendidikan dan lahirnya kesadaran etnis. Akhirnya, Toraja menjadi bagian dari Indonesia sejak 1942. Bagian ini membahas renegosiasi posisi Toraja di Sulawesi Selatan dan Indonesia. Terjadi perubahan pesat di bidang politik, sosial dan ekonomi.

Volkman dan Adams membahas perubahan di Toraja. Volkman (1985:6) menegaskan bahwa perubahan-perubahan yang dibahas Bigalke sejak kedatangan Belanda seperti pendidikan, Kritenisasi, peningkatan monetisasi, migrasi, dan pariwisata dan setelah menjadi Indonesia dimana UUD'45 melarang adanya perbudakan, telah mengubah hubungan antara performans ritual dan status sosial. Masyarakat kelas bawah yang telah mendapatkan uang dan pendidikan kembali ke kampung halamannya dan melakukan upacara kematian besar-besaran untuk keluarga dari kelas rendah.

Pariwisata mulai ada sejak tahun 1970 dan perubahan yang mencolok adalah adanya apa yang Adams (1988: 60) sebut antara lain homogenisasi dan estetisisasi budaya. Ia lebih bergerak ke seni dan meninggalkan ritual. Disamping itu terjadi proses dekontekstualisasi dan rekontekstualisasi yang terbuka untuk publik. Dalam situasi demikian masyarakat mengalami perubahan dari nilai ritual ke nilai eksibisi (Benjamin 1968 [1955]).

Tulisan-tulisan ini telah memberikan pemahaman yang mendalam tentang Agama Aluk To Dolo dan kebudayaan Toraja serta perubahannya namun tidak mengetengahkan masalah proses mendasar yang terjadi dalam pertemuan antara agama setempat dengan agama global, Kristen Protestan dan Katolik.

Timbul permasalahan: apa yang terjadi dalam interaksi antara agama Aluk To Dolo dengan agama Kristen Protestan dan Katolik? Bagaimana proses glokalisasi terjadi dalam interaksi kedua agama? Dan mengapa terjadi perubahan-perubahan dalam proses glokalisasi?

Berdasarkan masalah-masalah tersebut penelitian ini berfokus pada Glokalisasi Spasio-Temporal dalam Agama Aluk To Dolo oleh Agama Kristen di Toraja. Rasional penelitian ini adalah untuk memberikan pemahaman lebih dalam tentang proses interaksi dua agama lewat dialogisme yang berpusat pada keharmonisan spasio-temporal. Manfaat praktisnya ialah agar para ilmuan dapat merancang bagaimana melakukan pelestarian budaya-budaya lokal secara umum agar tidak tergilas oleh globalisasi. 
Sebagai sistem kepercayaan Aluk To Dolo masuk ke dalam sistem lapisan budaya tertinggi yaitu sistem kepercayaan yang berpengaruh ke dalam sistem nilai, norma dan perilaku serta ke dalam benda-benda. Secara umum, agama dapat didefinisikan sebagai

Dalam hal ini kebudayaan adalah serangkaian pemahaman dan kesadaran yang sedang dikonstruksi yang dipakai anggota-anggota masyarakat untuk menginterpretasi dunia sekelilingnya (Fox 1990). Atau semacam alat atau serangkaian skenario yang anggota - anggota masyarakat pakai untuk melaksanakan kehidupan sehari-harinya (Fox 1990:10).

Definisi ini cukup representatif karena terkandung di dalamnya tiga wujud kebudayaan. Setiap kebudayaan terdiri atas lapisan-lapisan yang dibedakan ke dalam tiga sistem yang saling berhubungan yaitu sistem pengetahuan dan kepercayaan, sistem nilai dan sistem makna, sistem perilaku sebagai perwujudan pengetahuan dan nilai serta sistem benda-benda.

Demikian pula, Koentjaraningrat mengemukakan tiga wujud kebudayaan seperti ide atau mental simbolik, tingka laku dan karya (Koentjaraningrat 1985[1974]):5). Penting membedakan ketiga lapisan budaya ini karena hanya dengan itu dapat dibedakan dengan jelas wujud budaya mana yang mendapatkan pengaruh globalisasi.

Agama dalam penelitian ini dipahami sebagai "organized effort to make virtue of our ultimate necessities" (upaya terorganisir untuk mencapai kebajikan kebutuhan hidup yang tertinggi) (Yinger 1957). Durkheim menyatakan bahwa agama terdiri dari dua hal yaitu kepercayaan yang mencakup representasi sakral dan ritual yang merupakan tindakan tertentu yang hanya digambarkan dalam representasi sakral tadi (Bell 1992; Durkheim 1915).

Teori yang dipakai adalah teori glokalisasi. Glokalisasi adalah konsep kompleks yang terdiri atas global dan lokal dalam batas Indonesia dan dunia. Inti penelitian membahas proses glokalisasi yaitu membangun keharmonisan antara yang global dan lokal, universal dan partikular, persamaan dan perbedaan. Akhirnya, yang dimaksud dengan spasio adalah ruang dan temporal menunjuk pada dimensi waktu. Gabungan antara keduanya tampaknya mencirikan proses glokalisasi budaya Toraja dengan budaya global.

Walaupun masih diperdebatkan kapan globalisasi mulai terjadi (ada yang katakan sejak dulu, ada yang katakan sejak abad 18), sebagai ide kunci ia muncul pada tahun 1990an (Waters 2000 [1995]) ketika Robertson mengingatkan kita akan pentingnya konsep ini dalam sosiologi (Robertson 1992). Penjelasan Robertson tentang globalisasi sebagai eskalasi saling ketergantungan global dan intensifikasi kesadaran global dalam memasuki millenium ketiga merupakan hal penting yang perlu digarisbawahi.

Proses globalisasi memainkan peranan penting dalam tiga arena kehidupan sosial yaitu ekonomi, politik, dan sosial budaya dimana ditemukan tiga tipe pertukaran (exchange).Waters menjelaskan hubungan bidang-bidang ini sebagai berikut (Waters 2000: 7-10). Dalam bidang pertukaran politik hubungan-hubungan itu dikembangkan ke territorial yang bertujuan untuk penduduk yang tinggal di kawasan itu, memakai sumbersumbernya untuk integrasi territorial atau ekspansi. Pertukaran politik ini memuncak dalam pembangunan batas teritorial yang sama dengan masyarakat bangsanegara. Pertukaran politik antar unit-unit ini cenderung mengukuhkan batas teritorial.

Akhirnya, pertukaran simbolis budaya berkaitan terutama dengan proses komunikasi dalam berbagai media oral, internet, publikasi, performans, pengajaran, hiburan, propaganda, iklan, ritual, eksibisi dan tontonan. Pertukaran simbolik ini membebaskan hubunganhububungan sosial dari ruang. Simbol-simbol dapat diproduksi di mana-mana pada waktu kapan saja. Pembatasan produksi dan reproduksi simbol minim. Karena simbol berkaitan erat dengan hal-hal fundamental tenteng manusia maka ada klaim nilai universalnya.

Globalisasi berpusat pada dua konsep penting yaitu saling keterhubungan (interconnectedness) dan deterritorialisasi (Fernandez 2009; Waters 2000 [1995]). Fernandez (2009: 7-8) memaparkan kedua konsep itu dengan meringkas berbagai pandangan ahli sebagai berikut. Lewat saling keterhubungan di berbagai bidang politik, ekonomi, sosial dan budaya kegiatan-kegiatan kehidupan sosial terhubungan sehingga dunia semakin sempit. Keterhubungan globalisasi mengubah tatanan lokal dengan membuat peristiwa-peristiwa jauh menjadi relevan ke dalam kehidupan lokal dan menciptakan ketergantungan antara yang lokal dan global.

Kemudian globalisasi dicirikan oleh deterritorialisasi yang menunjuk kepada kemungkinan-kemungkinan interaksi antar individu dan kelompok tanpa memandang lokasi. Semakin dunia saling terhubungkan semakin jarak dan lokasi bukan masalah dalam interaksi antar individu.

Appadurai menguraikan globalisasi ide lewat migrasi besar-besaran dan mediasi elektronik (Appadurai 2003). Appadurai (2003: 33-34) mengidentifikasi aliran ide dengan sufiks -scape, 'gambaran-gambaran mental yang diglobalkan tentang dunia sosial dari sudut aliran objek budaya'. Aliran-aliran ini meliputi antara lain: ethnoscape, distribusi individu-individu yang bergerak (wisatawan, migran, pengungsi dan lain-lain), teknoscape, distribusi teknologi finanscape, distribusi kapital, mediascape, distribusi informasi, dan ideoscape, distribusi ide politik dan nilai (kebebasan, demokrasi, dan hak-hak asasi manusia), serta sacriscape, distribusi ide-ide keagamaan dan nilai-nilai.

Yang paling cepat mengglobal adalah pertukaran simbol budaya yang berkaitan erat dengan hal-hal fundamental manusia dengan kleim nilai universalnya seperti agama, demokrasi, pendidikan dan cita rasa.

Seperti diketahui globalisasi digambarkan bersifat hegemonik terhadap warisan budaya termasuk agama lokal. Karena intensitasnya sangat tinggi, ia punya efek negatif pada warisan budaya sehingga dapat menghilangkan identitas. Namun pandangan ini dibantah dalam penelitian ini.

Glokal yang terdiri atas kata globe dan lokal adalah sebuah proses yang mengevaluasi pengaruhpengaruh global dalam konteks lokal.

Mengutip Friedman (Friedman 2000), Fernandez mengajukan glokalisasi sebagai berikut: 
The ability of a culture when it encounters other strong cultures, to absorb influences that naturally fit into and can enrich that culture, to resist those things that are truly alien and to compartementalize those things that, while different can nevertheles be enjoyed and celebrated as different (Fernandez 2009: 2; Friedman 2000: 295).

Metode bagaimana sebuah budaya termasuk agama melakukan glokalisasi dan evaluasi bervariasi dari budaya ke budaya. Ada kelompok yang merasa globalisasi menekan mereka yang dilakukan oleh hegemonisme masyarakat adidaya, tapi ada juga yang berupaya mengundangnya.

Selanjutnya Fernandez menjelaskan agama sudah melakukan glokalisasi apabila sudah melakukan pertukaran budaya, mengambil elemen-elemen dari agama lain yang meningkatkan dan memperkaya agama mereka dan menghindari elemen-elemen yang negatif. Misalnya proses meminjam dan menyelaraskan praktik-praktik asing, kepercayaan-kepercayaan dan produk-produk asing untuk disesuaikan dengan gaya hidup-gaya hidup budaya setempat adalah hal yang biasa dalam sejarah. Kebanyakan budaya-budaya dunia adalah budaya-budaya hibrid sebagai akibat dari pertukaran budaya dan glokalisasi.

Dalam proses glokalisasi budaya-budaya perlu persiapan dalam menghadapi kekuatan-kekuatan global. Hanya mampu menyaring mana yang cocok mana yang tidak cocok tidak cukup. Ia harus mampu mencari keseimbangan antara yang global dan lokal. Cara agama dan budaya melakukan glokalisasi ialah dengan 'dialogisme'. Dialog antar agama merupakan satu aspek penting glokalisasi (Fernandez 2009: 45-51).

\section{METODE}

Penelitian ini mengetengahkan hasil penelitian dari masyarakat Toraja yang dilakukan antara tahun 2005-2013. Toraja yang terletak $310 \mathrm{~km}$ di sebelah utara Propinsi Sulawesi Selatan dapat dicapai dengan mobil dengan menempuh perjalanan selama tujuh atau delapan jam dari kota Makassar.

Menurut sensus 2010 ketika penelitian ini dilakukan jumlah penduduk Toraja adalah 446.000 jiwa. Ada $70 \%$ penganut agama Protestan, 20\% Katolik, 5\% Aluk To Dolo, dan $5 \%$ beragama Islam. Namun, yang hidup di luar Toraja sekitar dua juta.

Toraja terletak di daerah pegunungan yang membuatnya sulit dicapai. Walaupun Belanda sudah berada di Sulawesi Selatan selama berabad-abad (abad ke 17), mereka baru sampai ke Toraja pada tahun 1905 (Van End 1994). Keadaan demikian membuat masyarakat ini terisolasi dan barangkali itu menjadi salah satu penjelasan mengapa mereka dapat mempertahankan agama, tradisi dan budaya mereka.

Penelitian ini membandingkan tiga kasus glokalisasi agama Aluk To Dolo yang dilakukan pengikut Kristen Toraja yaitu pranata tongkonan, sistem ritual dan seni patung. Proses glokalisasi dalam ketiga kasus itu memperlihatkan persamaan dan perbedaannya.
Metode berkaitan dengan masalah-masalah bagaimana mengajukan pertanyaan, bagaimana merancang penelitian, bagaimana menarik inferensi, dan bagaimana menganalisis data (Abbot 2004).

Bila didasarkan pada kategori pengumpulan data maka dalam penelitian ini metode yang dipakai adalah gabungan metode etnografi, survei dan sejarah. Metode etnografi merupakan pengumpulan data dimana peneliti terlibat langsung di lapangan berinteraksi dengan masyarakat yang diteliti yang dikenal dengan observasi partisipan (Spradley 1980; Sugiyono 2013). Metode survei dilakukan dengan mawawancarai sejumlah responden dan membaca sejumlah kecil laporan-laporan zending Belanda di Toraja. Penelitian di lakukan di berbagai kampung di Toraja Selatan yaitu di Makale, Sangalla' dan Mengkendek serta di Toraja Utara yaitu di Rantepao.

Bila dilihat dari kategorisasi penganalisisan data maka di sini dipakai interpreasi langsung terhadap data dan kadang digabung dengan analisis narasi.

\section{HASIL DAN PEMBAHASAN}

Penelitian ini menyeleksi tiga kasus dimana jelas masyarakat setempat melakukan glokalisasi terhadap agama Aluk To Dolo, yaitu dengan mendialogkan antara yang lokal dan yang universal Protestan dan Katolik. Berikut adalah gambaran hasil penelitian wawancara dengan tokoh-tokoh agama dan masyarakat serta para pemimpin agama Aluk To Dolo.

\section{Konsep Tongkonan}

Tongkonan dalam bahasa Toraja mempunyai banyak makna. Kata ini berasal dari kata dasar tongkon yang berarti 'duduk' (Veen 1972). Kata tongkon biasa dipakai untuk menggambarkan kegiatan menghadiri upacara kematian seseorang. Tongkonan adalah kata benda populer dipakai menamai rumah Toraja berbentuk unik dan berukir indah. Rumah tradisional ini termasuk yang banyak dibicarakan dalam literatur, misalnya pandangan tongkonan secara umum (Waterson 2009: 123-224), seni ukiran pada rumah (Sandarupa 1996b), nilai-nilai yang di belakangnya (Sandarupa 2002), tipe-tipe dan fungsinya (NooyPalm 1979).

Namun makna dasar kata tongkonan adalah kelompok sosial. Masyarakat Toraja menganut sistem kemasyarakatan bilateral yaitu seseorang menghitung garis keturunan baik pada sisi ibu maupun pada sisi bapak.

Segmen teks tradisi lisan Passomba Tedong, 'Litani Kerbau' berikut memperlihatkan tongkonan sebagai sistem kekerabatan:

1) La mendolok lamba' te tongkonanna to merrapu tallang

Akan berkembang tongkonan milik rumpun keluarga

2) Pakapa la mendolok lamba' te to merrapu tallang Dan akan berkembang rumpun keluarga ini Sumber:(Sandarupa 2013) 
Kelompok-kelompok sosial ini mengidentifikasi diri pada bentuk fisik rumah tradisional. Ciri-ciri yang ada pada tongkonan menggambarkan prestasi dan prestise pemilik tongkonan itu. Karena masyarakat Toraja sangat hierarkis yaitu bangsawan, menengah, dan orang biasa ciri hierarkis ini tampak bukan pada bentuk tongkonan melainkan pada sejumlah ornamen penanda pembeda. Tongkonan tertinggi disebut tongkonan layuk (mulia) pusat pemerintahan tradisional di masa silam. Tongkonan pesio' aluk adalah tongkonan yang berfungsi penyebar agama Aluk To Dolo di masa lampau. Kemudian ada tongkonan balimbing kalua' yaitu tongkonan yang pemiliknya kelompok pemberani atau militer. Akhirnya tongkonan batu a'riri merupakan tongkonan kelompok masyarakat biasa yang tidak berukir.

Tongkonan adalah pusat pengelolah berbagai pranata seperti pranata religi, pranata kekerabatan, pranata pendidikan, pranata peternakan, pranata kehutanan, dan pranata pertanahan.

Di masa lampau tongkonan didirikan oleh sepasang nenek. Ada yang lima, sepuluh, dua puluh bahkan tiga puluh generasi yang lalu. Nenek-nenek pendiri tongkonan inilah yang disembah sebagai dewa leluhur nenek moyang (to membali puang). Dalam perkembangannya antara generasi itu ada yang membangun tongkonan. Dengan demikian seseorang dapat menjadi anggota pada beberapa tongkonan.

Namun demikian, tongkonan juga merupakan bangunan religius seperti yang digambarkan dalam segmen teks dari mitos yang terdapat dalam Passomba Tedong, 'Litani Kerbau':

1). Kurre sumanga'na te banua dilindo puang, nani bendan bongana gau'

Terima kasih atas rumah berwajah Yang Kuasa, tempat melakukan upacara

2). Saba' parayanna te sondong dirupa deata, la nani tunannang samara bisara

Terima kasih atas bagian depan rumah berwajah Dewa tempat melakukan upacara

Sumber: (Veen 1965: 18)

Walaupun tentara Belanda sudah berada di Toraja sejak tahun 1905 van de Loosdrecht yang diutus oleh lembaga Gereformeerde Zendingsbond (GZB) yang didirikan 6 Februari 1901 di kota Utrecht baru masuk Toraja pada 22 Desember 1913. Sejak itu agama Kristen Protestan bersama pendidikan Barat diperkenalkan di Toraja (End 1994: 65). Menyusul Agama Katolik pada tahun 1937. Sejak itulah mulai terjadi dialog antara agama setempat Aluk To Dolo dan Agama Kristen Protestan dan Katolik.

Perkembangan terakhirkedua gereja mengembangkan teologi kontekstual (Rambe 2014). Agama Katolik menamainya inkulturalisme, suatu gerakan yang mengitegrasikan praktik budaya lokal ke dalam gereja (Liku Ada' 2013).

Salah satu yang dipertimbangkan adalah tongkonan. Seorang pendeta Protestan, Theodorus
Kobong menulis mengenai tongkonan yang dianggap sebagai pusat kebudayaan Toraja (Kobong 1989). Yang dikembangkan adalah tongkonan sebagai pranata religi dan kekerabatan. Gereja lokal sudah disebut tongkonan bukan dalam bentuk fisik melainkan dalam konsep. Bentuk gereja memang sudah ada yang memakai tongkonan berbentuk perahu. Namun sebagian lainnya bentuk bangunan.

Yang mengalami proses glokalisasi berkaitan dengan dua hal. Dalam konteks lokal tongkonan bertalian dengan pengelompokan sosial dari sisi keturunan ibu dan dari sisi keturunan bapak. Dalam konteks global tongkonan menjadi konsep "gereja" yang didefinisikan sebagai kumpulan umat. Dari unsur lokal keluarga sisi ibu dan bapak menjadi sesuatu yang universal. Aspek unsur universal lainnya yang diperkenalkan gereja yaitu bahwa nenek moyang tidak berhenti pada pendiri tongkonan tetapi pada Abraham bahkan sampai ke Tuhan. Van den End dalam laporannya sering menceriterakan tentang kegitan Van de Loosdrecht yang berceritera kepada masyarakat Toraja tentang nenek moyang Abraham, Noah, bahkan sampai Adam dan Hawa (End 1994: 80-93; lihat juga Bigalke 2005: 93).

Tongkonan sebagai pranata religi juga mengalami perubahan. Dalam konteks lokal tongkonan selalu dibangun dalam suatu orientasi kosmologi lokal yaitu dari hulu sungai ke muara sungai dan sisi matahari naik dan sisi matahari turun. Hulu dan sisi matahari naik dikaitkan dengan kehidupan sedangkan muara sungai dengan matahari terbenam dengan kematian. Kedua sisi itu merupakan ruang dan waktu yang mengatur pelaksanaan ritual kehidupan dan ritual kematian. Dari sudut agama Aluk To Dolo, ritual kehidupan berkaitan dengan pemujaan terhadap Dewa-Dewi Langit, Bumi, dan Bawah Bumi sedangkan ritual kematian berkaitan dengan Arwah Leluhur yang sudah menjadi Dewa di Langit (To Membali Puang). Dalam konteks global, tongkonan sebagai sistem kekerabatan yang sudah diubah tadi sebenarnya mengurangi kekuatan nenek moyang dan mengangkat turunan dan nenek moyang Yesus sebagai penggantinya. Perluasan ruang ke masa lamapu itu akhirnya semua berujung ke Tuhan Yang Esa. Glokalisasi pada tingkat ini mengubah faham Aluk To Dolo dari yang dualistis ke monoteistis.

\section{Sistem Ritual}

Ada beberapa cara masyarakat Toraja mengklasifikasi ritualnya (Sandarupa 2014b). Pertama, aluk tallu lolona a 'pa' toninna. Disebut tiga aluk karena ia meliputi upacara menyangkut manusia (aluk tau), upacara tanam-tanaman (aluk tananan), dan upacara menyangkut hewan (aluk patuan). Dikatakan empat karena di samping ketiga tembuni di atas ada lagi satu upacara yang disebut upacara menebus kesalahan (suru' pengkalossoran).

Yang keempat ini menyangkut manusia 1) umpakilala to ma'rapu (menyadarkan rumpun keluarga 2) ma'passande'-sande' (menyandarkan apa yang dicitakan 3) massarak-sarak 4) ma'pallin (upacara atas 
kekeliruan) 5) mangrambu langi' (menebus dosa) dan 6) rambu solo'.

Upacara yang menyangkut tanaman terutama padi. Biasa juga disebut ritual panaungan yaitu upacara tanam-tanaman yang dipimpin oleh pemimpinpemimpin adat, to bara', to parengnge' dan tomina yang dilakukan setiap tahun. Merupakan praktek aluk bersama dalam kampung dan biasanya dilakukan di tempat-tempat sakral tertentu antara lain di pedatuan, penammuan, pa'buaran dan lain-lain. Ada satu ritual padi yang disebut bua' pare yang dilakukan selama bertahun-tahun. Ada sejumlah ritual yang dilaksanakan di dalamnya seperti aluk Bugi' (upacara kerasukan), Aluk Maro (Upacara penyembuhan) dan lain-lain.

Ritual sanggemanawa (upacara makhluk bernafas) adalah ritual untuk hewan-hewan seperti ritual untuk kerbau (alukna sulu'na tedong); untuk babi (alukna pakandean bai); untuk ayam (alukna kurresan manuk); untuk anjing (alukna pakandean asu), dan benda-benda yang dianggap bernafas seperti ritual untuk rumah (alukna bangunan banua); ritual untuk lumbung (alukna alang dibando rara'); untuk emas (alukna bulawan matasak); untuk kain (alukna mawa' mate lu'pi'na); untuk wang (alukna oang mabilangan); untuk tempat upacara (alukna rante masangka'); untuk pasar (alukna tananan pasa'); untuk pohon enau (alukna induk sawang bunga); untuk mata air (alukna kalimbuang boba); untuk sawah (alukna tetean tampo); untuk tempat pesemaian padi (alukna pesungan banne sibidang).

Sebelum meyembelih ayam, babi dan kerbau, ada upacara yang dilakukan disertai dengan tuturan ritus seperti passuru' manuk, 'upacara ayam', passuru' bai, 'upacara babi' dan passomba tedong, 'upacara kerbau'. Teks-teks ini cukup panjang tapi yang terpanjang adalah teks passomba tedong yang teridiri atas ribuan baris.

Secara umum teks-teks ini didasarkan pada mitos penciptaan dengan mengutip bagian teks kenapa hewanhewan ini disembelih, yaitu perminaan izin kepada masing-masing leluhurnya dan pelaksanaan masingmasing fungsi sebagai saudara untuk tujuan menyembah dewa-dewa. Dan teks-teks ini menggambarkan bahwa semakin hewan ini dikorbankan dalam upacara semakin akan membuat sipemilik kaya misalnya tiap-tiap bagian kerbau tidak dilihat sebagai daging saja tetapi dapat mendatangkan rejeki sejauh manusia tidak serakah dalam pembantaiannya. Mulai dari muka kerbau sampai ekornya punya makna kekayaan emas dan kebangsawanan. Misalnya, tali kerbau akan mendatangkan tali emas, cocok hidung mendatangkan gelang emas, paru kerbau mendatangkan kain mawa' dan seterusnya.

Sedangkan upacara manusia disebut alukna ma'lolo tau. Aluk ini menunjang manusia di dunia selama hidupnya agar menjadi manusia sa'ti. Ritual makhluk manusia yang disebut ma'lolo tau terdiri atas:

a) alukna takinan pia (upacara bayi)

b) alukna ma 'rampanan kapa' (perkawinan)

c) alukna to ma 'karandang kalua' (upacara bepergian mencari rezeki)

Aluk ma 'lolo tau merupakan fase kehidupan yang dilihat sebagai suatu perkembangan dari taraf rendah ke taraf tinggi. Aluk ini yang terlengkap dibandingkan dengan aluk lolo lain. Karena pada a'pa' toninna (Empat Tembuni) itulah tingkat elaborasi ritual untuk lolo tau menjadi sangat penting.
Yang paling terkenal adalah pasangan ritual yang disebut rambu solo'/rambu tuka' yang secara umum diterjemahkan upacara kematian/upacara kehidupan (Sandarupa 2012[1986]). Ritual ini dimulai dengan ritual kematian dan dilanjutkan dengan ritual kehidupan untuk mentransformasi arwah nenek moyang untuk menjadi dewa-to membali puang (Sandarupa 2012: 36)

Glokalisasi terjadi sebagai berikut. Untuk mengadopsi praktik lokal ke dalam gereja sejumlah ritual telah dilarang terutama yang berkaitan dengan upacara menyangkut Dewa-Dewa sebagai sumber rezeki. Upacara kematian juga telah diedit dari yang kompleks ke yang sederhana. Misalnya, upacara bangsawan yang dilakukan dua kali dijadikan sekali saja. Upacara yang berlangsung berhari-hari bahkan bertahun disederhanakan menjadi satu kali saja dan tidak diikuti lagi upacara kelanjutan hidup arwah yang akan menjadi Dewa To Membali Puang di langit. Yang menjadi dikenal di luar adalah upacara kematian.

Demikian juga, tongkonan sebagai pusat pelaksanaan ritual direduksi ke tempat pelaksanaan ritual kematian tanpa pasangannya lagi ke ritual kehidupan. Hal ini terjadi akibat sistem kepercayaan bahwa arwah orang mati langsung menghadap Tuhan ketika seseorang meninggal. Akibatnya, ritual kehidupan (rambu tuka') ditiadakan dalam Aluk To Dolo.

\section{Patung, Foto, dan Nenek Moyang}

Bagian ini sudah didiskusikan dalam Kongres Kebudayaan Indonesia 2013 dan dalam berbagai seminar. Berikut bagian ini diambil dan diberi tambahan catatan dari Sandarupa (Sandarupa 2014a). Agama-agama besar seperti Protestan dan Katolik berinteraksi dengan agama lokal Aluk To Dolo (Agama Leluhur). Para zending menilai bahwa agama lokal ini perlu dimurnikan dari kepercayaan pada takhyul ke kepercayaan universal Yesus Kristus. Karena itu persoalan utama yang mereka hadapi adalah persoalan inkulturasi satu aspek dari glokalisasi warisan agama. Dalam proses itu sinkretisme, yaitu menempatkan kedua sistem kepercayaan itu secara bersamaan, sedapat mungkin dihindari.

Satu praktik yang ditolak adalah pembuatan patung atau tau-tau untuk orang mati kelas menengah ke atas pada upacara kematian karena terdapat perbedaan besar tentang konsep arwah dalam kedua agama. Konsep arwah dalam Aluk To Dolo jauh lebih kompleks ketimbang konsep arwah dalam paham Kristen. Dalam konteks lokal, tau-tau adalah badan baru arwah calon dewa. Dalam Singgi', 'pujian' tomina atau pendeta Aluk To Dolo dikatakan bahwa tau-tau representasi badan baru nenek moyang dengan menceriterakan riwayat hidupnya di depan patung mulai dari kehamilan sampai kembali ke langit: Waktu dihamilkan dan dilahirkan:

1) Tang dikandian maessu', tang dileran bua kayu Tidak diidamkan buah asam, tidak juga bua pohon

2) To dadi dao pussakna, dao bubungna dewata Dilahirkan di atas puncak, di atas bubungan Dewa 
Waktu sudah sampai ke langit dan turun ke bumi memberi berkat1) La turun la tiallenna Akan turun dari atas

2) Mananna' tokkonan layuk, ubanan pa'kalandoan Akan berkembang tongkonan mulia, capai umur panjang

3) Mananna' pa'bala tedong Akan banyak kandang kerbau

4) Napokendek bura padang saba' lelloan lembang Akan berlimpah hasil pertanian, berjumlah banyak hasil dari kampung

Sumber: (Sandarupa 1996a; Sandarupa 1995)

Tau-tau ini merupakan praktik Aluk To Dolo penginggalan budaya Austronesia. Mulai dari pemilihan pohon sampai pembuatannya disertai dengan ritual dan korban ayam dan babi. Ada juga upacara massabu tau-tau, yaitu upacara melantik tau-tau menjadi badan baru dewa yang sudah lengkap upacaranya. Lalu ia disemayamkan di sisi kiri mayat selama semalam untuk menangkap arwah si mati. Seperti yang kita ketahui tujuan suatu upacara kematian-rambu solo' Aluk To Dolo adalah untuk mentransformasi bombo (arwah yang menakutkan) menjadi bombo mendeatanna (arwah setengah dewa) di Puya dan lewat masseroi, mensucikan arwah dan keluarga yang ditinggalkan yang kemudian diikuti upacara rambu tuka', bombo mendeatanna menjadi mendeatanna, 'dewa' (untuk orang menengah ke bawah) dan mengkapuanganna, menjadi Puang). Dengan kata lain, upacara kematian bertujuan mentransformasi arwah menjadi dewa yang badan barunya adalah tau-tau. Tau-tau ini ditempatkan di atas balkon secara berjejer di dekat liang tempat mengurburkan mayat yang kemudian sangat terkenal dan menarik wisatawan ke Toraja. Rambu solo' dan rambu tuka' menciptakan nenek moyang ke depan. Dewa-dewa ini sangat dipercayai kekuatannya oleh penganut Alukta.

Hal-hal inilah yang membuat pihak gereja mencap praktik ini sebagai kepercayaan tahyul, sehingga selama beberapa dekade patung-patung ini dilarang pemakaiannya dalam upacara kematian.

Keadaan berubah ketika kesadaran baru muncul untuk menemukan kembali tradisi yang sudah ditinggalkan. Konsep universal arwah yang langsung menghadap Tuhan, suatu ajaran Calvin dan Luther, kemudian diterima dan ditunjang oleh universalisme teknologi kamera yang diperkenalkan ke daerah itu sejak kedatangan Belanda. Terjadilah reinterpretasi dengan mendialogkan yang lokal dan global.Pemakaian patung dibolehkan gereja kembali sejauh tau-tau tersebut foto almarhum. Dengan kata lain penekanannya pada representasi suatu momen kehidupan almarhum sebagaimana layaknya makna foto. Perubahan konsep ini menyebabkan terjadinya perubahan pada ciri-ciri patung yang dibuat. Muncullah artis gaya baru dengan karya gaya realistik. Untuk itu patung dibuat sesuai dengan wajah almarhum posisi tangan berubah. Semua ciri dualitas Alukta diubah ke ciri monoteis Kristen seperti posisi tangan dan lain-lain.

Singkatnya, glokalisasi terjadi pada konsep waktu. Bila patung Aluk To Dolo berfungsi untuk menjadi badan baru pada Leluhur di masa mendatang, maka patung Kristem mengekstensi waktu ke masa lampau. Foto adalah satu momen kehidupan di masa lampau. Dengan demikian glokalisasi menggabung dua dimensi waktu, masa lampau ditambah tanpa menghapuskan masa akan datang.

Dari ketiga studi kasus sudah dapat diperlihatkan persamaan dan perbedaan. Ketiga kasus punya persamaan dengan titik pusat permasalahan konsep spiritual yang berbeda dalam kedua agama. Konsep spiritual Aluk To Dolo berbeda dari konsep Kristen. Agama Aluk To Dolo menganut sistem dualistis yaitu kepercayaan pada kekuatan leluhur yang setelah upacara lengkap menjadi dewa di langit dan kepercayaan pada adanya dewa-dewa langit, bumi dan bawah bumi. Agama Kristen menganut sistem monoteisme, Allah satu adanya. Karena itu kekuasaan dewa-dewa dan arwah nenek moyang melemah. Hal ini berpengaruh pada lapisan kedua kebudayaan yaitu tingkah laku ritual. Tingkah laku ritual dipertahankan minus konsep spiritualitas lokal dan direduksi pada adat. Dalam hal itu unsur global bersifat hegemonik.

Namun masyarakat Kristen memakai berbagai strategi untuk mempertahankan unsur agama lokalnya. Strategi itu memakai metode penambahan dan bukan pengurangan. Dalam kasus tongkonan, nenek moyang pendiri tongkonan tidak dihilangkan tetapi dapat diperpanjang ke nenek moyang orang Kristen pada umumnya. Dalam kasus sistem ritual, pelaksanaan sebagian ritus-ritus tradisional dipertahankan dan pelaksanaan ritus Kristen dilakukan pada permulaan dan penutupan upacara tradisional. Dalam kasus pembuatan patung, praktik ini tidak dihilangkan tetapi boleh mengganti gaya pemahat dari patung idealistik ke patung realistik, dari simbolik ke ikonik.

\section{SIMPULAN}

Berdasarkan hasil penelitian di atas sudah dapat ditarik beberapa kesimpulan. Pertama, globalisasi yang selalu digambarkan bersifat hegemonik pada agama dan budaya lokal ternyata tidak berlaku umum. Masyarakat Toraja memperlihatkan bahwa elemen agama global dapat diterima sejauh tidak menghilangkan identitas agama lokal.

Kedua, masyarakat setempat juga mempunyai kearifan lokal dalam membangun keharmonisan kedua elemen agama dengan rekayasa pada dimensi spasiotemporal.

Ketiga, dengan demikian sudah bisa diajukan teori glokalisasi sebagai berikut: glokalisasi adalah kemampuan masyarakat mengintegrasikan dua elemen agama dan budayanya dengan memakai strategi kearifan lokal keharmonisan, penambahan elemen unsur global tanpa menghapus yang lokal, dengan perekayasaan pada dimensi spasiotemporal budaya. Berbeda dengan pandangan Fernandez yang mengikuti Friedman di atas ciri utama glokalisasi di Toraja adalah keharmonisan tanpa menolak elemen asing atau menghapus yang lokal. Teori ini juga sudah menspesifikasi lebih lanjut pada tingkat mana penggabungan kedua elemen terjadi yaitu pada spasio-temporal.

\section{DAFTAR PUSTAKA}

Abbot 2004 Discovery methods. Chicago: The University of Chicago Press.

Acciaioli, Greg 1985 Culture as art: From practice to 
spectacle in Indonesia. Canberra Anthropology 8 (1 \& 2):148-190.

Adams, Kethleen, Marie1988 Carving a new identity: ethnic and artistic change in Tana Toraja, Indonesia, University of washington.

- 1990 Cultural commoditization in Tana toraja, Indonesia. Cultural Survival Quarterly 14 (1):31-34.

- 1991 Distant encounters: Travel literature and the shifting images of the Toraja of Sulawesi, indonesia. Terrae Incognitae 23:81-92.

Appadurai, Arjun 2003 Modernity at large: cultural dimensions of globalization. Minneapolis, London: University of Minnesota Press.

Bell, Catherine 1992 Ritual theory, ritual practice. New York: Oxford University Press.

Benjamin, Walter 1968 [1955] Illuminations. New York: Schocken Books.

Bigalke, Terance W 2005 Tana Toraja: a social history of an Indonesian people. Singapore: Singapore University Press.

Crystal, Eryc 1989 Tourism in Toraja (Sulawesi, Indonesia). In Hosts and guests. V.L. Smith, ed. Philadelphia: University of Pennsylvania Press.

Durkheim, E 1915 The elementary forms of religious life. New York: Macmillan.

Fernandez, Sarah Elizabeth 2009 A theory of cultural glocality, University of Florida.

Fox, Richard G 1990 Nationalist ideologies and the production of national cultures. Washington D.C.: American Ethnological Society Monograph Series Number 2.

Friedman, Thomas 2000 The lexus and the Olive tree: understanding globalization. New York: Random House.

Kobong, Theodorus 1989 Evangelium und tongkonan: eine undersuchung uber die begegnung zwischen Chisticher botschaft und der kultur der Toraja.

Koentjaraningrat 1985[1974] Kebudayaan, mentalitas, dan pembangunan. Jakarta: PT Gramedia.

Koubi, Jeaninnine 1982 Rambu solo', la funmee descend: le cults de morts chez les Toradja du Sud. Paris: Centre Nationalde la Recherce Scientific.

Liku Ada', Mgr 2013 Konsep kinallo lalan dalam budaya Toraja. Sauan Sibarrung, Toraja, 2013.

Nooy-Palm, Hetty 1979 The Sa'dan Toraja. A study of their social life and religion: Organization, symbols and beliefs. The Hague: Martinus Nijhoff.

— 1986 The Sa'dan Toraja: a study of their social life and religion. Rituals of the east and west. Dordrecht: Foris Publications.
Rambe, H Aguswati 2014 Kontekstual Keterjalinan dalam Keterpisahan. Makassar: Penerbit Oase Intim.

Robertson, R 1992 Globalization. London: Sage.

Roxana, Waterson 2009 Path and rivers. Leiden: KITLV.

Sandarupa, Satnislaus 1996a Toraja's ancestral 'tau-tau' figures. In The Jakarta Post, April 25, 1996. Jakarta.

— 1996b Torajan architecture: order in symbolic designs. In The Jakarta Post, April 25, 1996. Jakarta.

- 2002 Membangun keutuhan dalam tongkonan: nilai. Kombongan Kalua' pada tanggal 14 September 2002, Dalam rangka peringatan Hari Jadi Toraja di Makassar Golden Hotel, Makassar, 2002. Unpublished.

- 2007 Tradisi lisan dan kearifan lokal Toraja. In Harian Kompas 5 Oktober 2007. Jakarta.

1995 Singgi’ tau-tau. Unpublished.

- 2004 The exemplary center: poetics and politics in the kingly death ritual in Toraja south Sulawesi Indonesia. Dissertation, The University of Chicago.

- 2012[1986] Life and death in Toraja. Makassar: Hasanuddin University Press.

— 2013 Passomba Tedong. Koleksi Pribadi.

- 2014a Kebudayaan Toraja, modal bangsa milik dunia. Sosiohumaniora 16(1):1-9.

- 2014b Keterputusan dan keterhubungan benang dalam budaya tallu lolona di Toraja. OASE, Makassar, $2014 b$.

Spradley, James P 1980 Participant observation. USA: Holt Rinehart and Wiston.

Sugiyono, 2013 Metode penelitian kuantitatif kualitatif dan R \& D. Bandung: Penerbit Alfabeta.

Van End, den 1994 Sumber-sumber zending tentang sejarah gereja Toraja 1901-1961. Jakarta: PT BPK GUNUNG MULIA.

Veen, van der 1965 The Merok feast of the Sa'dan Toraja. 's - Gravenhage: Martinus Nijhoff.

- 1966 The Sa'dan Toraja chant for the deceased. s' Gravenhage: Martinus Nijhoff.

Veen, van der and J Tammu 1972 Kamus Toradja Indonesia. Rantepao, Toraja: Jajasan Perguruan Kristen Toradja.

Volkman, Toby 1985 Feasts of honor: ritual and change in the Toraja highlands. Urbana and Chicago: University of Illinois Press.

Waters, Malcom 2000 [1995] Globalization. London and New York: Routledge.

Yinger, J. Milton 1957 Religion, society, adn the individual: an introduction to the sociology of religion. New York: The Macmillan Company. 